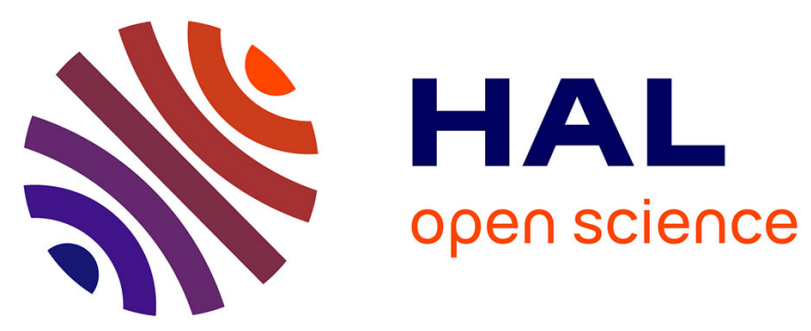

\title{
Inhabiting plant roots, nematodes, and truffles- Polyphilus, a new helotialean genus with two globally distributed species
}

Samad Ashrafi, Dániel G Knapp, Damien Blaudez, Michel Chalot, Jose G Maciá-Vicente, Imre Zagyva, Abdelfattah A Dababat, Wolfgang Maier, Gabor Kovacs

\section{To cite this version:}

Samad Ashrafi, Dániel G Knapp, Damien Blaudez, Michel Chalot, Jose G Maciá-Vicente, et al.. Inhabiting plant roots, nematodes, and truffles- Polyphilus, a new helotialean genus with two globally distributed species. Mycologia, 2018, 110 (2), pp.286 - 299. 10.1080/00275514.2018.1448167 . hal01827181

\section{HAL Id: hal-01827181 \\ https://hal.science/hal-01827181}

Submitted on 5 Jul 2018

HAL is a multi-disciplinary open access archive for the deposit and dissemination of scientific research documents, whether they are published or not. The documents may come from teaching and research institutions in France or abroad, or from public or private research centers.
L'archive ouverte pluridisciplinaire HAL, est destinée au dépôt et à la diffusion de documents scientifiques de niveau recherche, publiés ou non, émanant des établissements d'enseignement et de recherche français ou étrangers, des laboratoires publics ou privés. 
Inhabiting plant roots, nematodes and truffles-Polyphilus, a new helotialean genus with two globally distributed species

Samad Ashrafi ${ }^{1,2 *}$, Dániel G. Knapp ${ }^{3 *}$, Damien Blaudez ${ }^{4}$, Michel Chalot ${ }^{5,6}$, Jose G. Maciá-Vicente ${ }^{7,8}$, Imre Zagyva ${ }^{9}$, Abdelfattah A. Dababat ${ }^{10}$, Wolfgang Maier ${ }^{1}$, Gábor M. Kovács ${ }^{3} * *$

${ }^{1}$ Institute for Epidemiology and Pathogen Diagnostics, Julius Kühn-Institut (JKI) - Federal Research Centre for Cultivated Plants, Braunschweig, Germany

${ }^{2}$ Department of Ecological Plant Protection, Faculty of Organic Agricultural Sciences, University of Kassel, Witzenhausen, Germany

${ }^{3}$ Department of Plant Anatomy, Institute of Biology, Eötvös Loránd University, Pázmány Péter sétány 1/C, H-1117 Budapest, Hungary

${ }^{4}$ Université de Lorraine, UMR CNRS 7360 Laboratoire Interdisciplinaire des Environnements Continentaux, Faculté des Sciences et Technologies, BP 70239, F-54506 Vandoeuvre-lès-Nancy, France.

${ }^{5}$ Université de Bourgogne Franche-Comté, UMR CNRS 6249 Laboratoire Chrono-Environnement, Pôle Universitaire du Pays de Montbéliard, 4 place Tharradin, BP 71427, F-25211, Montbéliard, France.

${ }^{6}$ Université de Lorraine, Faculté des Sciences et Technologies, BP 70239, F-54506, Vandoeuvre-lèsNancy, France.

${ }^{7}$ Institute of Ecology, Evolution and Diversity, Goethe Universität Frankfurt, Max-von-Laue-Str. 13, 60438 Frankfurt am Main, Germany

${ }^{8}$ Integrative Fungal Research Cluster (IPF), Frankfurt am Main, Germany

${ }^{9}$ Nefag Rt. Nagykunsági Forestry and Wood Industry Rt., Szolnok, Hungary

${ }^{10}$ CIMMYT (International Maize and Wheat Improvement Centre), P.K.39 06511 Emek, Ankara, Turkey

* equally contributed

** corresponding author

\section{ARTICLE HISTORY:}

Received XX Month 2017, Accepted XX Month 20XX

\section{KEY WORDS:}

Leotiomycetes, Hyaloscyphaceae, taxonomy, systematics, endophyte, lifestyle

\section{ABSTRACT}


Fungal root endophytes, including the common form-group of dark septate endophytes (DSEs), represent different taxonomic groups and potentially diverse life strategies. In this study, we investigated two unidentified helotialean lineages found previously in a study of DSE fungi of semiarid grasslands, from several other sites, and collected recently from a pezizalean truffle ascoma and from eggs of the cereal cyst nematode Heterodera filipjevi. The taxonomic positions and phylogenetic relationships of 21 isolates with different hosts and geographic origins were studied in detail. Four loci (ITS, partial 18S nrRNA, 28S nrRNA and RPB2 genes) were amplified and sequenced for molecular phylogenetic analyses. Analyses of similar ITS sequences found in public databases revealed that the two lineages are globally distributed and have been detected in several biomes in different geographic regions. The host interaction of isolates from nematodes was examined using in vitro bioassays, which revealed that the isolates could penetrate the nematode cysts and colonize the eggs of $H$. filipjevi as observed in field-collected samples. Neither conidiomata and conidia nor ascomata formation could be detected in any of the isolates from various sources. Based on the results of morphological and molecular phylogenetic analyses, these isolates were found to represent a distinct lineage within the Helotiales in the Hyaloscyphaceae. For this lineage, we propose here the new genus Polyphilus represented by two new species, $P$. sieberi and P. frankenii.

\section{INTRODUCTION}

Fungal endophytes asymptomatically colonize plant tissues for a period of their life cycle (Petrini 1991; Saikkonen et al. 1998). They belong to different taxonomic groups and might represent diverse trophic strategies (Rodriguez et al. 2009; Porras-Alfaro and Bayman 2011). Dark septate endophytes (DSEs) compose a form-group of root endophytic fungi with melanized, septate intraradical hyphae (Jumpponen and Trappe 1998). DSE fungi can be found in several orders of Ascomycotina such as Helotiales, Xylariales and Pleosporales (see Sieber and Grünig 2013; Andrade-Linares and Franken 2013). DSEs belonging to Helotiales (class Leotiomycetes) are among the most widespread and common root endophytes, like the members of the well-known Phialocephala fortinii s.l.-Acephala applanata species complex (PAC) and several Cadophora species (Grünig et al. 2008; Sieber and Grünig 2013).

Helotiales is the largest and most diverse order in the Leotiomycetes, with approximately 395 genera belonging to 13 families (Wang et al. 2006). Helotialean fungi show diverse life styles: they can be saprobes, parasites of different organisms, endophytes colonizing a broad spectrum of plants, or plant mutualist symbionts $\mathrm{s}$ forming ectomycorrhizas or ericoid mycorrhizas, as in the case of Pezoloma ericae (syn. Rhizoscyphus ericae) (Wang et al. 2006). Although most helotialean species produce small apothecia, root endophytes have no clear teleomorph connections (Wang et al. 2006). Novel helotialean genera and species are continuously being described in association with a variety of plant hosts and organs; for example, endophytes of pine foliage and shoots (Yuan and Verkley 2015), 
and DSE fungi in the roots of grasses and pines (Walsh et al. 2014, 2015) or associated with horsetail shoots (Baral and Haelewaters 2015).

Two unidentified helotialean phylotypes were detected in a study about root-colonizing fungi from semiarid sandy grasslands of Hungary (Knapp et al. 2012). One lineage, referred to as the "DSE2 group", comprised 11 strains isolated from various host plants. The group was considered a DSE group based on in vitro re-synthesis tests, in which the isolates colonized roots, formed microsclerotia and caused no visible negative effect on the plant (Knapp et al. 2012). The other unidentified helotialean root-associated fungus was represented by only one isolate, REF050, classified in the "DSE-5 group". This fungus was not considered a DSE based on previous criteria (Knapp et al. 2012). At the time of that study, no nrDNA ITS1-5.8S-ITS2 (ITS barcode) or nrDNA 28S (LSU) sequences were found in public databases with high BLAST similarity to those from REF050. In contrast, sequences of the DSE-2 group were highly similar or identical to sequences of fungi mainly originating from soil and roots of a variety of plants from different continents (Knapp et al. 2012). Later, Glynou et al. (2015) isolated endophytes from roots of Microthlaspi spp. from a wide range of localities in Europe and Turkey, and found some isolates with ITS sequences highly similar to those of DSE-2. These isolates were classified within the operational taxonomic unit (OTU) OTU037, which was sixth in frequency out of the 44 helotialean OTUs obtained in the study (Glynou et al. 2015). Lacercat-Didier et al. (2016) isolated endophytes from ectomycorrhizal poplar roots collected from a metal-contaminated site in France, some of which also showed high sequence similarities to both the DSE-2 clade and the DSE-5 lineage. All those isolates were able to colonize roots of hybrid Populus in re-synthesis experiments. The clade including these and other sequences was described as a "new endophytic putative species belonging to the Helotiales" (Lacercat-Didier et al. 2016).

Further strains with high ITS sequence similarity to the DSE-2 clade were isolated from two additional sources: the inner tissue of a truffle ascoma collected from a Hungarian grassland similar to the habitats of the original DSE-2 isolates, and eggs of the cereal cyst nematode (CCN) Heterodera filipjevi originating from the Central Anatolian Plateau of Turkey.

We studied the isolates mentioned above to assess the taxonomic novelty of the strains and to determine their phylogenetic relationships. To accomplish this, we carried out a polyphasic taxonomic study using multilocus phylogenetic analyses and morphological comparisons. The results reinforced our original assumptions that these fungi belong to novel taxa; thus, we describe here a new genus with two novel species. In addition, given the natural occurrence of isolates inside nematode eggs, we examined their interaction with nematodes using in vitro bioassays.

\section{MATERIALS AND METHODS}

\section{Origin of isolates}

A total of 21 isolates belonging to the DSE-2 group and two isolates belonging to the DSE-5 group sensu Knapp et al. (2012) originating from different hosts and geographic regions (TABLE 1) were 
examined in the present study. The sampling sites were previously described in Kovács and Szigetvári (2002), Knapp et al. (2012), Glynou et al. (2015), Lacercat-Didier et al. (2016) and Ashrafi et al. (2017).

Pezizalean truffle ascomata (Hydnobolites cf. sp.) found by a trained truffling dog were collected under Festuca, Stipa, Juniperus, Populus, and Salix plants on a semiarid sandy grassland close to Csévharaszt, Hungary during autumn 2015. In the laboratory, the ascomata were carefully washed and broken in half in a sterile box. Small $(2-3 \mathrm{~mm})$ tissue pieces from the freshly broken surfaces were placed on modified Melin-Norkrans medium (MMN, Marx 1969) and kept in the dark at room temperature. After $10 \mathrm{~d}$, small pieces of the mycelia growing out from the tissues were transferred onto new medium. Two isolates with similar colony morphology originating from two different tissue parts were kept for further characterization.

\section{Fungal isolation from nematode eggs}

Cysts of H. filipjevi were collected from the rhizosphere of wheat plants. Cysts were extracted from root and soil samples using the modified flotation method (Coyne et al. 2007), directly handpicked from the extracted suspensions under a dissecting microscope, and stored at $4 \mathrm{C}$ until use. The cysts were examined using a dissecting microscope to separate healthy (homogenously brown) or empty cysts from symptomatic cysts (i.e. cysts bearing black eggs). Fungi were isolated from symptomatic cysts as described in Ashrafi et al. (2017).

\section{Sporulation and morphology of isolates}

To induce sporulation, isolates were cultured on MMN, malt extract agar (MEA), potato dextrose agar (PDA), synthetic nutrient-poor agar (SNA), oatmeal agar (OA), cornmeal agar (CMA) (see Crous et al. 2009), minimal media (MM) (de Vries et al. 2004) and Murashige-Skoog agar (MS, Murashige and Skoog 1962, M5524, Sigma-Aldrich Co. LLC., USA) in 9-cm Petri dishes. All cultures were incubated at room temperature in the dark. The majority of strains were kept at low temperature (5-6 C) for 11 months. Isolates were also cultured on autoclaved stems of stinging nettle (Urtica dioica), as sexual morphs of another DSE could be induced on these (see Knapp et al. 2015). Horsetail (Equisetum arvense) shoots were also used, because a phylogenetically related species was described from this substrate (see Baral and Haelewaters 2016). Colony blocks of representative isolates were floated in sterile water for 5 wk. Colony morphology was assessed on MMN, MEA, PDA and CMA media. Agar plates were inoculated in three replicates with 4-mm diameter mycelial plugs of each isolate in 6-cm Petri dishes at room temperature and the colonies were examined after $3 \mathrm{wk}$.

\section{DNA extraction and amplification}

Genomic DNA was extracted from fungal mycelia using a modified CTAB method (Murray and Thompson 1980; Kovács et al. 2001) or the E.Z.N.A. ${ }^{\circledR}$ Fungal DNA Mini Kit (OMEGA Bio-tek, 
Norcross, Georgia) following the manufacturer's instructions. To extract fungal DNA from nematode eggs, single eggs were transferred to 1.5-ml Eppendorf microtubes containing $5 \mu 1$ DNA-free water, $40 \mathrm{mg}$ sterile silica sand and four steel beads. Each sample was first air-dried under a laminar flow, frozen by dipping the tubes in liquid nitrogen, and homogenized at $50 \mathrm{~Hz}$ for $2 \mathrm{~min}$ (Qiagen TissueLyser LT, Hilden, Germany). Freezing and homogenization were repeated three times. DNA was then extracted using the Qiagen DNeasy Plant Mini kit following the manufacturer's instructions.

The ITS, partial LSU, 18S nrRNA (SSU), and partial RNA Polymerase II Second Largest Subunit (RPB2) regions of the isolates were amplified using DreamTaq ${ }^{\circledR}$ polymerase (Thermo Fisher Scientific, Lithuania). The ITS and LSU regions of nrDNA were amplified using the primer pair ITS1F (Gardes and Bruns 1993) and ITS4 (White et al. 1990), and the primers LR0R (Rehner and Samuels 1994) and LR5 (Vilgalys and Hester 1990), respectively, as described previously (Kovács et al. 2008). The primers NS1 and NS4 (White et al. 1990) were used to amplify the SSU region, and the partial RPB2 region was amplified using the primer pair RPB2-6F and RPB2-7R (Liu et al. 1999). Sequencing of the amplicons was carried out with the primers used for amplification by LGC GmbH (Berlin, Germany), Eurofins Genomics (Ebersberg, Germany) and GATC Biotech (Konstanz, Germany).

The sequences were compiled from electropherograms using the Pregap4 and Gap4 tools of the STADEN software package (Staden et al. 2000) and SEQUENCHER 5.4 (GeneCodes Corporation, Ann Arbor, MI), respectively, and deposited in GenBank (XY123456-XY123456) (for the reviewers: here and later in the ms: all database depositions-GenBank, TreeBase, MycoBank, Strain collections-will be done after the review to avoid any superfluous work changing names and/or dataset changes). The sequences obtained were compared with sequences in public databases using BLASTn searches (http://blast.ncbi.nlm.nih.gov/Blast.cgi) (Altschul et al. 1990).

\section{Phylogenetic analyses}

Three datasets were prepared for phylogenetic analyses: (i) an order-level dataset was used to study the phylogenetic position of the isolates among related helotialean taxa; (ii) a second dataset was established to study the intra-group phylogenetic relationships of the isolates studied here; (iii) the third dataset included representative ITS sequences of our isolates and similar sequences obtained from public databases via a BLAST search.

Alignments of our sequences and the sequences of corresponding entries from GenBank (TABLE S1) were assembled using the E-INS-i method in MAFFT version 7 (Katoh and Standley 2013). The alignments were checked and edited with MEGA6 (Tamura et al. 2013) and deposited in TREEBASE (study XXX; www.treebase.org). For the three datasets, multi-locus phylogenetic Bayesian analyses were performed with MRBAYES 3.1.2 (Ronquist and Huelsenbeck 2003) using the GTR+G nucleotide substitution model. Four Markov chains were run for 10000000 generations and sampled every 1000 generations with a burn-in value set at 6000 sampled trees. Topological convergence was 
checked by AWTY online (Nylander et al. 2008). Maximum likelihood (ML) phylogenetic analyses were carried out with the RAXMLGUI 1.3 (Silvestro and Michalak 2012) implementation of RAXML (Stamatakis 2014). The GTR $+\mathrm{G}$ nucleotide substitution model was used for the partitions with ML estimation of base frequencies, and a ML bootstrap analysis with 1000 replicates was used to test the support for the branches. The phylogenetic trees were visualized and edited using MEGA6 (Tamura et al. 2013).

The ITS, LSU, SSU and RPB2 sequences were used for order-level phylogenetic analyses, and considered as four partitions. These four regions were used to determine the intra-group phylogenetic relationships of our isolates with the methods described above. To improve phylogenetic resolution, indels in the ITS region were coded (Nagy et al. 2012) using the simple indel coding algorithm (Simmons et al. 2001; Young and Healy 2003) with the program FASTGAP (Borchsenius 2009). In the Bayesian analysis, the two-parameter Markov (Mk2 Lewis) model was used for the indel partition of the dataset and the GTR+G model for the nucleotide partitions. In the ML analyses, in addition to the nucleotide partitions $(\mathrm{GTR}+\mathrm{G})$, the indel data were treated as binary data (BIN). The third dataset comprised only ITS sequences of representative DSE-2 isolates and similar GenBank sequences; the parameters and methods used for phylogenetic analyses were the same as mentioned above.

\section{Pathogenicity against $\mathrm{H}$. filipjevi}

To assess the pathogenicity of the isolates (17A and 17C) originating from nematode cysts against $H$. filipjevi, in vitro tests were performed to fulfill Koch's postulates. For this, healthy cysts or eggs were placed either directly on or at the edge of fungal colonies, or a modified version of Riddell's slide culture technique (Gams et al. 1998) was applied to test the ability of the obtained isolates to colonize H. filipjevi eggs. The details of the tests are described in Ashrafi et al. (2017).

\section{Light microscopy}

Symptomatic cysts and eggs of $H$. filipjevi were mounted in water and examined with an Olympus SZX 12 dissecting microscope and a Zeiss Axioskop 2 plus compound microscope using Nomarski Differential Interference Contrast (DIC); both were equipped with a Jenoptik ProgRes ${ }^{\circledR}$ digital camera (Jenoptik, Jena, Germany). Nematode cysts and eggs were photographed in water. Microscopic photographs were recorded using the CAPTUREPRO 2.8 software (Jenoptik), and the images were processed using the Adobe PHOTOSHOP software CS 5.1 


\section{RESULTS}

Sporulation and colony morphology

All isolates showed similar colony morphology, growth characteristics and color. The colonies on MMN media were slow-growing, radially striate, and bright cream to white; no exudates were present (FIG. 1). Numerous media and culture conditions were tested and different autoclaved plant organs were inoculated to induce sporulation. Neither conidiomata nor conidia nor ascomata formation could be detected. As the cultures aged, spherical monilioid cells formed in the colonies on MMN. No sporulation of the strains was observed in any of the media or conditions tested, or in the four different laboratories where the strains were isolated, maintained and kept e.g. at 4-7 C for 6-18 months before this study.

\section{Molecular phylogeny}

Based on the results of the order-level phylogenetic analyses, the clade containing the isolates studied here was unambiguously grouped in the order Helotiales, within the poorly resolved family Hyaloscyphaceae s.l. (FIG. 2). The fungi grouped with different incertae sedis clades and several distinct genera (FIG. 2). The clade comprising our isolates formed a monophyletic group with Belonioscyphella hypnorum, Cistella sp., C. albidolutea, Leohumicola sp., L. minima, L. verrucosa, Psilachnum sp., P. staphyleae, Rodwayella citrinula, Rommelaarsia flavovirens, Roseodiscus rhodoleucus, R. subcarneus, Tricladium angulatum and Urceolella carestiana. However, this clade only received strong support by Bayesian inference, and was not significantly supported by bootstrapping in the RAXML analysis.

The intra-group phylogenetic analyses of the isolates studied here revealed two well-supported clades (FIG. 3). The first clade comprised the majority of isolates (19) with moderate intra-clade heterogeneity (FIG. 3). The second clade included two isolates, REF050 and V16. The difference in the ITS and RPB2 sequences of the two clades was 2.8-3.3\% and 3.1-3.3\%, respectively. The results of the molecular phylogenetic analyses reinforced our hypothesis that this clade represents a novel helotialean genus, in which we describe two species.

Several identical or nearly identical ITS sequences deposited in public databases were found during similarity searches of the ITS sequences of our strains. These similar sequences represent uncultured fungi and isolates derived mainly from soil and roots of various host plants (FIG. 4). Both clades of our isolates grouped with sequences originating from different geographic and climatic regions and from different continents (FIG. 4). The first clade contained the majority of our isolates, including those that originated from nematode eggs and truffles. These grouped with sequences obtained mainly from plant-associated fungi (FIG. 4). The second clade, comprising our REF050 and V16 isolates, included sequences originating mostly from plant-associated fungi, soil samples, and stromata of the entomopathogenic fungus Ophiocordyceps sinensis (FIG. 4). 


\section{TAXONOMY}

Polyphilus D.G. Knapp, Ashrafi, W. Maier \& Kovács, gen. nov.-MycoBank MB123456; FIGS. 1-5

The genus Polyphilus contains species associated with plant roots as endophytes, plant parasitic nematodes and truffles. Isolates can be collected from surface-sterilized roots, surfacesterilized nematode eggs, and truffle ascomata, and can be cultured and maintained on general media. These fungal isolates do not produce fruiting bodies or spores of any kind.

Etymology: Polyphilus, from the ancient Greek words "poly" (more than one, much and many) and "philia" (brotherly love, like, having an affinity for something), referring to the fact that the strains of the species have been isolated from many different sources and geographic regions.

Type species: Polyphilus sieberi

Notes-Colony morphology is quite similar among Polyphilus spp. including shape, growth characteristics, color and absence of sexual and asexual spores (FIG. 1). Colonies are radially striate, bright grey to white and slow-growing (FIG. 1). Isolates were collected from surface-sterilized roots of common juniper (Juniperus communis), sprawling needle sunrose (Fumana procumbens), common milkweed (Asclepias syriaca), tree of heaven (Ailanthus altissima), Helianthemum ovatum, hybrid poplar (Populus deltoides $\times$ P. nigra), scots pine (Pinus sylvestris), Microthlaspi perfoliatum, M. erraticum, Microthlaspi sp., from surface-sterilized eggs of the CCN Heterodera filipjevi, and from a truffle (cf. Hydnobolites sp.) ascoma.

Polyphilus sieberi D.G. Knapp, Ashrafi, W. Maier \& Kovács, sp. nov.-MycoBank MB123456; FIGS. 1-5

Typification: HUNGARY, Fülöpháza, Asclepias syriaca, July 2008, D.G. Knapp \& G.M. Kovács, REF052 = strain no. XX, (holotype H, deposited to herbarium of the ...).

Etymology: We name this species in honor of Dr. Thomas N. Sieber, who has contributed significantly to our knowledge on root endophytes and DSE fungi.

Colonies on MMN slow-growing, 2.4-3.4 mm diam after $21 \mathrm{~d}$ in the dark; raised, surface smooth or with sparse aerial mycelium, even margins, colony radially striate and wrinkled, bright grey to white, creamy, no exudates, no medium staining; pale amber reverse; cultures sterile. Colonies on MEA slow-growing, 2-2.8 mm diam after $21 \mathrm{~d}$ in the dark; centrally elevated, dense aerial mycelium, colony radially striate and wrinkled with lobate margins, light grey to smoke, no exudates; iron gray reverse; cultures sterile (FIG. 1).

Phylogenetically, Polyphilus, currently comprising P. sieberi and P. frankenii, forms a wellsupported monophyletic group that clusters incertae sedis within Hyaloscyphaceae.

Polyphilus sieberi (strain no. XX) differs from one of its closest phylogenetic neighbors, Urceolella carestiana (TNS-F18014), by unique fixed alleles in the ITS, LSU and RPB2 loci based on alignments of each locus deposited in TreeBASE as study X12345: ITS positions: 83 (deletion), 171 
(T), $415(\mathrm{C}), 424(\mathrm{G}), 449$ (T), 488 (A); LSU positions: 445 (C), 520 (C); RPB2 positions: $124(\mathrm{G})$, 295 (C), 313 (C), 397 (C), 445 (T), 616 (T), 700 (A).

Specimens examined. HUNGARY, Fülöpháza, in roots of Asclepias syriaca, July 2008, D.G. Knapp \& G.M. Kovács (holotype permanently preserved in a metabolically inactive state), (REF052 = strain no. XX); in roots of Fumana procumbens, (REF051 = strain no. XX); Tatárszentgyörgy, in roots of Ailanthus altissima, $($ REF053 = strain no. XX); Fülöpháza, in roots of Helianthemum ovatum, April 2008, (REF054 = strain no. XX); in roots of Juniperus communis, $($ REF056 = strain no. XX); July 2008, $($ REF057 = strain no. XX); Tatárszentgyörgy, $($ REF058 = strain no. XX); Fülöpháza, $($ REF059 = strain no. XX); in fruiting bodies of Hydnobolites cf. sp., November 2015, (TT3A = strain no. XX); ibid., (TT3B = strain no. XX); FRANCE, Evin-Malmaison, in roots of Populus deltoides $\times$ P. nigra hybrid, June 2011, D. Blaudez \& M. Chalot, (M3 = strain no. XX); Pierrelaye, (P02 = strain no. XX); ibid., (P06 = strain no. XX); TURKEY, Yozgat, in eggs of Heterodera filipjevi, August 2013, S. Ashrafi, $(17 \mathrm{~A}=$ strain no. $\mathrm{XX})$; ibid., $(17 \mathrm{C}=$ strain no. $\mathrm{XX})$; BULGARIA, Diviya, in roots of Microthlaspi erraticum, May 2013, K. Glynou \& J.G. Maciá-Vicente, (P1582 = strain no. XX); FRANCE, Challement, in roots of Microthlaspi sp., (P2020 = strain no. XX); Vivonne, in roots of Microthlaspi perfoliatum, $(\mathrm{P} 2262=$ strain no. XX); ibid., $(\mathrm{P} 2418=$ strain no. XX).

Polyphilus frankenii D.G. Knapp, Ashrafi, W. Maier \& Kovács, sp. nov. — MycoBank MB123456; FIGS. 1-3, 5

Typification: HUNGARY, Bugac, in roots of Juniperus communis, April 2008, D.G. Knapp \& G.M. Kovács, REF050 = strain no. XX, (holotype H, deposited to herbarium of the ...).

Etymology: We name this species in honor of Dr. Philipp Franken, who has contributed significantly to our knowledge on root endophytes and DSE fungi and on their interaction with plants.

Colonies on MMN slow-growing, $2.5 \mathrm{~mm}$ diam after $21 \mathrm{~d}$ in the dark; raised, surface smooth or with sparse aerial mycelium, even margins, colony radially striate and wrinkled, light grey to white, no exudates, no staining of the medium; pale amber reverse; cultures sterile. Colonies on MEA slowgrowing, $2.2 \mathrm{~mm}$ diam after $21 \mathrm{~d}$ in the dark; centrally elevated, dense aerial mycelium, colony radially striate and wrinkled with lobate margins, light gray to smoke, no exudates; iron gray reverse; cultures sterile (FIG. 1).

P. frankenii (strain no. XX) differs from P. sieberi (strain no. XX) by unique fixed alleles in the ITS, LSU, SSU and RPB2 loci based on alignments of each locus deposited in TreeBASE as study X12345: ITS positions: 115 (T); 116 (T), 159 (T), 187 (C), 191 (T), 222 (A), 424 (C), 430 (G), 455 (T), 493 (A), 499 (A), 500 (C), 517 (T); LSU positions: 471 (C), 545 (T), 546 (C); RPB2 positions: 54 (T), 71 (C), 80 (A), 126 (G), 147 (G), 156 (C), 180 (T), 276 (A), 297 (C), 315 (C), 348 (C), 399 (C), $444(\mathrm{G}), 447(\mathrm{~A}), 588(\mathrm{G}), 618(\mathrm{G}), 699(\mathrm{C}), 702(\mathrm{~A}), 770(\mathrm{C}), 783(\mathrm{~A}), 785(\mathrm{~A}), 787(\mathrm{~A}), 792(\mathrm{G})$.

Specimens examined. HUNGARY, Bugac, in roots of Juniperus communis, April 2008, D.G. Knapp \& G.M. Kovács, (holotype permanently preserved in a metabolically inactive state (REF050 = 
strain no. XX); FRANCE, Villerupt, in roots of Pinus sylvestris, November 2011, D. Blaudez \& M. Chalot, $(\mathrm{V} 16=$ strain no. XX).

Isolation of Polyphilus sieberi from H. filipjevi

Isolates $17 \mathrm{~A}$ and $17 \mathrm{C}$ were obtained from naturally infected eggs of $H$. filipjevi. In infected cysts, the fungus caused black discoloration, which could clearly be seen using a stereomicroscope. Infected cysts contained mostly dark brown eggs, which were entirely colonized by distinctly septate, moniliform, thick-walled, and strongly melanized hyphae (FIG. 5 A, B). Some infected eggs displayed no discoloration and were found to be colonized by hyaline hyphae containing numerous oil-like bodies (FIG. 5 C). When cultured on PDA, mycelium emerged from infected eggs and formed greengrayish to olivaceous gray cultures.

Pathogenicity of Polyphilus sieberi against $\mathrm{H}$. filipjevi

In vitro tests revealed that isolates $17 \mathrm{~A}$ and $17 \mathrm{C}$ could penetrate the nematode cysts and colonize the eggs of H. filipjevi (FIG. 5 D). Cysts placed directly on the fungal mycelium were entirely colonized by 'runner hyphae' growing in the cyst mucilage (FIG. 5 E). The colonization of eggs of the incubated cysts or eggs placed on or in the vicinity of the fungal mycelium was initiated by the formation of enlarged, irregularly lobed and hyaline or lightly pigmented hyphae containing many oil-like bodies; these hyphae eventually occupied the entire host body cavity (FIG. 5 F, G). Infected eggs became pigmented upon fungal development, from pale greenish gray to greenish brown (FIG. $5 \mathrm{~F}, \mathrm{H}$ ). The artificially infected eggs resembled naturally infected samples (FIG. 5 A).

Slide culture-based observations revealed that eggs were infected within 7-10 d after placing them on the margin of a growing mycelium. Infection started with individual hyphae penetrating the egg and nematode body cavity. Following penetration, the hyphae developed and formed enlarged cells filled with oil-like structures and destroyed the egg content (FIG. 5 I, J). Accumulation of oil-like structures was generally more extensive in the hyaline hyphae than in the pigmented ones. The fungus could also enter the body cavity of juvenile nematodes through natural openings such as the mouth aperture (FIG. $5 \mathrm{~J})$.

\section{DISCUSSION}

The two species of the new genus described here belong to Helotiales and appear nested in a diverse group in the Hyaloscyphaceae s.l. (FIG. 2). The new taxa are grouped within a clade that comprises most of the taxa of "Clade-9" sensu Han et al. (2014), which contained Cistella sp., C. albidolutea, Psilachnum sp., P. staphyleae, Rodwayella citrinula, Urceolella carestiana and U. crispula. However, in our analyses $U$. crispula did not group with members of Clade-9, but formed a clade with Calycina herbarum and Calycellina populinum, which belonged to "Clade-2" in Han et al. (2014). Clade-9 received strong support in Han et al. (2014), but in our analysis the group was only supported by 
Bayesian inference when supplemented with further genera (Belonioscyphella, Leohumicola, Rommelaarsia, Roseodiscus). The representatives belonging to Clade-9 (Han et al. 2014) were collected from various materials and do not exhibit any unifying morphological characteristics. In contrast, the concepts of the individual genera within this group are based on teleomorph morphology (e.g. Han et al. 2009). Species within the clade with Polyphilus spp. were isolated from diverse substrates: the Psilachnum species were collected from tree leaves (Han et al. 2014), Urceolella carestiana was collected from the rachis of a maiden fern (Thelypteris nipponica) (Han et al. 2014) and Cistella sp. was obtained from a corncob (Zea mays). Both Cistella albidolutea and Rodwayella citrinula were isolated from the sheath of a Carex plant. Belonioscyphella hypnorum is a necrotrophic parasite of various mosses and develops apothecia mostly on stems in the upper part of shoots (Huhtinen et al. 2010). Roseodiscus species can be isolated from mosses and horsetail ferns in bogs and swamps and might be both parasitic and saprotrophic (Baral and Krieglsteiner 2006). Rommelaarsia flavovirens produces apothecia on dead stems of Equisetum (Baral and Haelewaters 2015). Leohumicola species are soil fungi isolated from heated soils in Canada (Hambleton et al. 2005). Tricladium angulatum is a freshwater fungus isolated from foam (Baschien et al. 2006) that represents a distinct clade among Tricladium species (Baschien et al. 2006; Campbell et al. 2009) and seems to have affinity to Hyaloscyphaceae s.l. (Campbell et al. 2009). Only Leohumicola and the Polyphilus spp. were mainly isolated from soils or underground materials in semiarid regions; all other representatives of the clade were isolated from aboveground parts of land plants and from humid habitats. Thus, the species of this clade tend to occur in humid to wet habitats in swamps, wet soils and even in freshwater, inhabiting mosses, ferns, horsetails, sedges and water plants (Baral and Krieglsteiner 2006; Baral and Haelewaters 2015; Han et al. 2014; Campbell et al. 2009). In contrast, the majority of Polyphilus isolates described in this study were collected in semiarid regions such as the isolates from roots and truffles in sandy grasslands, from roots of semiarid poplar stands and from $\mathrm{CCN}$ eggs in the semiarid Central Anatolian plateau. However, the sequences from public databases clustering with the two Polyphilus species described here represent mainly root-inhabiting fungi with more diverse habitat and host origins (FIG. 4).

There has been a continuous increase in taxon numbers in Helotiales, but the last comprehensive order-level analysis was published more than a decade ago (Wang et al. 2006). Although family-level analyses and studies have been carried out (e.g. Han et al. 2014) and nomenclatural recommendations and clarifications have been published (Johnston et al. 2014), the statement in the $10^{\text {th }}$ edition of the Dictionary of the Fungi (Kirk et al. 2008) that "the taxonomy of the order is unsettled, and molecular data are inadequate to elucidate relationships in many cases" seems to be still valid.

Although $P$. sieberi and $P$. frankenii differed significantly in each locus examined, the morphology of the two species was highly similar. They shared growth characteristics and could not produce spores on the different media and tissues tested, like the majority of DSE fungi (Sieber and 
Grünig 2013). Hyphal branching and spherical monilioid cells developed as the colonies of both species aged, which was also reported previously (Lacercat-Didier et al. 2016).

The new species $P$. frankenii was represented by two isolates originating from plant roots. Based on the results of a previous re-synthesis experiment, REF050 isolated from surface-sterilized roots of Juniperus communis was not considered a DSE (Knapp et al. 2012). The fungi represented by ITS sequences forming a clade with $P$. frankenii originated from several continents and mainly from roots, whereas only a few were isolated from soil directly. In contrast, the isolates belonging to $P$. sieberi were considered DSEs based on in vitro colonization tests (Knapp et al. 2012), and were even more diverse in origin. Other root-associated P. sieberi isolates originated from poplar (LacercatDidier et al. 2016) and Microthlaspi spp. (Glynou et al. 2015), respectively. Isolates originating from a truffle ascoma also belonged to P. sieberi. Truffles can be complex microhabitats hosting bacteria, yeasts and filamentous fungi that can be isolated from healthy and intact ascomata (Pacioni and Leonardi 2016). For example, Pacioni et al. (2007) isolated filamentous fungi from fresh and healthy truffles and found several ascomycetes and basidiomycetes, including some entomopathogenic and endophytic species.

Different genera and species of fungal entomopathogens and parasites of other invertebrates have been reported as naturally occurring fungal endophytes (Vega 2008; Sikora et al. 2008). Several insect-parasitic fungi such as Acremonium, Beauveria and Metarhizium species have been detected in healthy organs of different plant species (Vega et al. 2008; Barelli et al. 2016; Foulon et al. 2016). These fungi mainly belong to the order Hypocreales, which contains endophytic and insect-parasitic representatives sharing common ancestors (Spatafora et al. 2007; Gao et al. 2011). It was also reported that the colonization of plants by particular endophytic fungi can improve the defense of the host toward nematodes (Schouten 2016), and provide nutrient benefits to the host plant (Behie et al. 2012, 2017; Barelli et al. 2016). Although the possible interactions of nematodes with class-1 and class-2 endophytes sensu Rodriguez et al. (2009) were discussed previously (Rodriguez et al. 2009; Schouten 2016), no nematode-parasitic fungus has yet been reported from the class-4 endophytes comprising DSE fungi. Thus, to our knowledge $P$. sieberi is the first DSE, as well as the first helotialean fungal species, reported to colonize the eggs of a plant-parasitic nematode.

Nematode cysts protect the eggs from adverse environmental conditions. DSEs are considered abundant in habitats with harsh environmental conditions including alpine, arctic, arid and semiarid regions (Mandyam and Jumpponen 2005; Rodriguez et al. 2009). For root-colonizing soil fungi, cysts or truffle ascomata may serve as microenvironments where they have better conditions for survival. The interior mucilaginous matrix of cyst nematodes has been reported to contain some glycoconjugates and lectins (Nour et al. 2003), the latter of which is assumed to play a role in nematode recognition by fungi ( $\mathrm{Li}$ et al. 2015). The mucilage complex of plant roots was also reported to contain carbohydrates that are involved in water storage, and thus protecting the roots and perhaps 
root-colonizing fungi from desiccation (Barrow 2003). It might be hypothesized that the colonization of cyst mucilage by P. sieberi can help the fungus to avoid potential desiccation.

Observations from our in vitro experiments showed that isolates belonging to $P$. sieberi could entirely colonize the cyst cavity by growing "runner hyphae" into the cyst mucilage. After penetration of the egg, the hyphal cells differentiated into distinct moniliform, thick-walled cells filled with oildroplet structures, which were absent in the runner hyphae. These structures might be involved in nutrient acquisition and translocation from the host (Jumpponen and Trappe 1998, Barrow 2003), as well as in nematode-killing and degradation of nematode body components (Nordbring-Hertz et al. 2006). Nematode colonization by P. sieberi might therefore provide advantages for nematode host plants, by directly killing eggs and thus reducing the parasite load or by transferring nutrients from the degraded eggs and juveniles to the plant as was reported for the endophytic fungus Metarhizium robertsii and insects (Behie et al. 2012).

Polyphilus, the novel genus described here, is a globally distributed Hyaloscyphaceae genus derived from soils that is primarily associated with plant roots based on the specimens isolated here and on the conspecific or congeneric fungal sequences identified from public databases. Nevertheless, two distinct isolation sources - nematode cysts and a truffle ascoma - suggest that these fungi might also colonize other organisms in soil. The ecological functions of these interactions as well as possible multitrophic interactions should be tested in experimental systems.

\section{ACKNOWLEDGEMENTS}

This work was supported by the Hungarian Scientific Research Fund (NKFIH/OTKA K109102), the Deutsche Gesellschaft für Internationale Zusammenarbeit (GIZ) and the International Maize and Wheat Improvement Centre (CIMMYT). The project was also supported by the French ANR Research Program [grant number ANR BIOFILTREE 2010-INTB-1703-01 to MC] and by the Agence de l'Environnement et de la Maitrise de l'Energie (ADEME) [grant number PROLIPHYT 1172C0053 to MC]. JGMV acknowledges LOEWE (Landes-Offensive zur Entwicklung Wissenschaftlichökonomischer Exzellenz) of the state of Hesse for financial support within the framework of the Cluster for Integrative Fungal Research (IPF). Special thanks go to the Fiat Panis Foundation, Germany (stiftung-fiat-panis.de) for a "PhD completion stipend" to SA. We appreciate Dr. Shaun R. Pennycook's help in nomenclatural issues.

\section{REFERENCES}

Altschul SF, Gish W, Miller W, Myers EW, Lipman DJ. 1990. Basic local alignment search tool. Journal of Molecular Biology 215: 403-10.

Andrade-Linares DR, Franken P. 2013. Fungal endophytes in plant roots: taxonomy, colonization patterns, and functions. In: Aroca R eds. Symbiotic Endophytes, Soil Biology. Berlin: Springer. p. $311-334$. 
Ashrafi S, Helaly S, Schroers H-J, Stadler M, Richert-Poeggeler KR, Dababat AA, Maier W. 2017. Ijuhya vitellina sp. nov., a novel source for chaetoglobosin A, is a destructive parasite of the cereal cyst nematode Heterodera filipjevi. PLoS ONE 12: e0180032

Baral HO, Haelewaters D. 2015. Rommelaarsia flavovirens gen. et sp. nov. (Helotiales), a new discomycete on Equisetum with a peculiar asexual state. Ascomycete.org 7: 321-330.

Baral HO, Krieglsteiner L. 2006. Hymenoscyphus subcarneus, a little known bryicolous discomycete found in the Białowieża National Park. Acta Mycologica 41: 11-20.

Barelli L, Moonjely S, Behie SW, Bidochka MJ. 2016. Fungi with multifunctional lifestyles: endophytic insect pathogenic fungi. Plant Molecular Biology 90: 657-664.

Barrow JR. 2003. Atypical morphology of dark septate fungal root endophytes of Bouteloua in arid southwestern USA rangelands. Mycorrhiza 13: 239-247.

Baschien C, Marvanová L, Szewzyk U. 2006. Phylogeny of selected aquatic hyphomycetes based on morphological and molecular data. Nova Hedwigia 83: 311-352.

Behie SW, Zelisko PM, Bidochka MJ. 2012. Endophytic insectparasitic fungi translocate nitrogen directly from insects to plants. Science 336: 1576-1577.

Behie SW, Moreira CC, Sementchoukova I, Barelli L, Zelisko PM, Bidochka MJ. 2017. Carbon translocation from a plant to an insect-pathogenic endophytic fungus. Nature Communications 8: 14245.

Borchsenius F. 2009. FastGap 1.2. Software distributed by the authors at: http://www.aubot.dk/FastGap_home.htm.

Campbell J, Marvanova L, Gulis V. 2009. Evolutionary relationships between aquatic anamorphs and teleomorphs: Tricladium and Varicosporium. Mycological Research 113: 1322-1334.

Coyne DL, Nicol JM, Claudius-Cole B. 2007. Practical plant nematology: a field and laboratory guide, Cotonou, Benin: SP-IPM Secretariat, International Institute of Tropical Agriculture (IITA).

Crous PW, Verkley GJM, Groenewald JZ, Samson RA, eds. 2009. Fungal Biodiversity. CBS Laboratory Manual Series, Centraalbureau voor Schimmelcultures, Utrecht, The Netherlands 1: 1269.

de Vries RP, Burgers K, van de Vondervoort PJI, Frisvad JC, Samson RA, Visser J. 2004. A new black Aspergillus species, A. vadensis, is a promising host for homologous and heterologous protein production. Applied and Environmental Microbiology 70: 3954-3959.

Foulon J, Zappelini C, Durand A, Valot B, Blaudez D, Chalot M. 2016. Impact of poplar-based phytomanagement on soil properties and microbial communities in a metal-contaminated site. FEMS Microbiology Ecology 92: fiw163.

Gams W, Hoekstra ES, Aptroot A. 1998. CBS course of mycology, Baarn Centraalbureau voor Schimmelcultures.

Gao Q, Jin K, Ying SH, Zhang Y, Xiao G, Shang Y, Duan Z, Hu X, Xie XQ, Zhou G, Peng G, Luo Z, Huang W, Wang B, Fang W, Wang S, Zhong Y, Ma LJ, St Leger RJ, Zhao GP, Pei Y, Feng MG, Xia Y, Wang C. 2011. Genome sequencing and comparative transcriptomics of the model entomopathogenic fungi Metarhizium anisopliae and M. acridum. PLoS Genetics 7: e1001264.

Gardes M, Bruns TD. 1993. ITS primers with enhanced specifity for Basidiomycetes - application to the identification of mycorrhizae and rusts. Molecular Ecolology 2: 113-118.

Glynou K, Ali T, Buch A-K, Haghi Kia S, Ploch S, Xia X, Çelik A, Thines M, Maciá-Vicente JG. 2015. The local environment determines the assembly of root endophytic fungi at a continental scale. Environmental Microbiology 18: 2418-2434. 
Grünig CR, Queloz V, Sieber TN, Holdenrieder O. 2008. Dark septate endophytes (DSE) of the Phialocephala fortinii s.l.-Acephala applanata species complex in tree roots: classification, population biology, and ecology. Canadian Journal of Botany 86: 1355-69.

Hambleton S, Nickerson NL, Seifert KA. 2005. Leohumicola, a new genus of heat-resistant hyphomycetes. Studies in Mycology 53: 29-52.

Han JG, Hosoya T, Sung GH, Shin HD. 2014. Phylogenetic reassessment of Hyaloscyphaceae sensu lato (Helotiales, Leotiomycetes) based on multigene analyses. Fungal Biology 118: 150-167.

Han JG, Park MJ, Shin HD. 2009. Psilachnum staphyleae, a new member of foliicolous Hyaloscyphaceae from Korea. Mycotaxon 110: 219-224.

Huhtinen S, Laukka T, Döbbeler P, Stenroos S. 2010. Six novelties to European bryosymbiotic discomycetes. Nova Hedwigia 90: 413-431.

Johnston PR, Seifert KA, Stone JK, Rossman AY, Marvanová L. 2014. Recommendations on generic names competing for use in Leotiomycetes (Ascomycota). IMA Fungus 5: 91-120.

Jumpponen A, Trappe JM. 1998. Dark septate endophytes: a review of facultative biotrophic rootcolonizing fungi. New Phytologist 140: 295-310.

Katoh K, Standley DM. 2013. MAFFT Multiple sequence alignment software version 7: improvements in performance and usability. Molecular Biology and Evolution. 30: 772-80.

Kirk PM, Cannon PF, Minter DW, Stalpers JA. 2008. Dictionary of the Fungi. 10 ${ }^{\text {th }}$ ed. CABI p. 771.

Knapp DG, Kovács GM, Zajta E, Groenewald JZ, Crous PW. 2015. Dark septate endophytic pleosporalean genera from semiarid areas. Persoonia 35: 87-100.

Knapp DG, Pintye A, Kovács GM. 2012. The dark side is not fastidious - dark septate endophytic fungi of native and invasive plants of semiarid sandy areas. PLOS ONE 7: e32570.

Kovács GM, Rudnóy S, Vágvölgyi C, Lásztity D, Rácz I, Bratek Z. 2001. Intraspecific invariability of the ITS region of rDNA of Terfezia terfezioides in Europe. Folia Microbiologica 46: 423-426.

Kovács GM, Szigetvári C. 2002. Mycorrhizae and other root-associated fungal structures of the plants of a sandy grassland on the Great Hungarian Plain. Phyton 42: 211-223.

Kovács GM, Trappe JM, Alsheikh AM, Bóka K, Elliott TF. 2008. Imaia, a new truffle genus to accommodate Terfezia gigantea. Mycologia 100: 930-939.

Lacercat-Didier L, Berthelot C, Foulon J, Errard A, Martino E, Chalot M, Blaudez D. 2016. New mutualistic fungal endophytes isolated from poplar roots display high metal tolerance. Mycorrhiza 26: $1-15$.

Li J, Zou C, Xu J, Ji X, Niu X, Yang J, Huang X, Zhang KQ. 2015. Molecular mechanisms of nematode-nematophagous microbe interactions: basis for biological control of plant-parasitic nematodes. Annual Review of Phytopathology 53: 67-95.

Liu YL, Whelen S, Hall BD. 1999. Phylogenetic relationships among ascomycetes: evidence from an RNA polymerase II subunit. Molecular Biology and Evolution 16: 1799-1808.

Mandyam K, Jumpponen A. 2005. Seeking the elusive function of the root-colonising dark septate endophytic fungi. Studies in Mycology 53: 173-189.

Marx DH. 1969. The influence of ectotrophic mycorrhizal fungi on the resistance of pine roots to pathogenic infection. I. Antagonism of mycorrhizal fungi to root pathogenic infection fungi and soil bacteria. Phytopathology 59: 153-163.

Murashige T, Skoog F. 1962. A revised medium for rapid growth and bioassays with tobacco tissue cultures. Physiologia Plantarum 155: 473-497.

Murray MG, Thompson WF. 1980. Rapid isolation of high molecular weight plant DNA. Nucleic Acids Research 8: 4321-4325. 
Nagy LG, Kocsubé S, Csana Z, Kovács GM, Petkovits T, Vágvölgyi C, Papp T. 2012. Re-mind the gap! Insertion-deletion data reveal neglected phylogenetic potential of the nuclear ribosomal internal transcribed spacer (ITS) of fungi. PLoS ONE 7: e49794.

Nordbring-Hertz B, Jansson HB, Tunlid A. 2006. Encyclopedia of Life Sciences. Chichester, UK: Wiley.

Nour SM, Lawrence JR, Zhu H, Swerhone GDW, Welsh M, Welacky TW, Topp E. 2003. Bacteria associated with cysts of the soybean cyst nematode (Heterodera glycines). Applied and Environmental Microbiology 69: 607-615.

Nylander JA, Wilgenbusch JC, Warren DL, Swofford DL. 2008. AWTY (are we there yet?): A system for graphical exploration of MCMC convergence in Bayesian phylogenetic inference. Bioinformatics 24: 581-583.

Pacioni G, Leonardi M, Aimola P, Ragnelli AM, Rubini A, Paolocci F. 2007. Isolation and characterization of some mycelia inhabiting Tuber ascomata. Mycological Research 111: 14501460 .

Pacioni G, Leonardi M. 2016. Truffle-Inhabiting Fungi. In: Zambonelli A, Iotti M, Murat C, eds. True Truffle (Tuber spp.) in the World. Switzerland: Springer International Publishing.

Petrini O. 1991. Fungal endophytes of tree leaves. In: Andrews JH, Hirano SS, eds. Microbial Ecology of Leaves. New York: Springer-Verlag. p. 179-197.

Porras-Alfaro A, Bayman P. 2011. Hidden fungi, emergent properties: endophytes and microbiomes. Annual Review of Phytopathology 49: 291-15.

Rehner SA, Samuels GJ. 1994. Taxonomy and phylogeny of Gliocladium analysed from nuclear large subunit ribosomal DNA sequences. Mycological Research 98: 625-634.

Rodriguez R, White J, Arnold A, Redman R. 2009. Fungal endophytes: diversity and functional roles. New Phytologist 182: 314-330.

Ronquist F, Huelsenbeck JP. 2003. MrBayes 3: Bayesian phylogenetic inference under mixed models. Bioinformatics 19: 1572-1574.

Saikkonen K, Faeth SH, Helander M, Sullivan TJ. 1998. Fungal endophytes: A continuum of interactions with host plants. Annual Review of Ecology Evolution and Systematics 29: 319-343.

Schouten A. 2016. Mechanisms involved in nematode control by endophytic fungi. Annual Review of Phytopathology 54: 121-142.

Sieber TN, Grünig CR. Fungal root endophytes. 2013. In: Wasel Y, Eshel A, Kafkafi U, eds. Plant Roots: The Hidden Half. New York: Marcel Dekker. p. 1-49.

Sikora RA, Pocasangre L, zum Felde A, Niere B, Vu TT, Dababat AA. 2008. Mutualistic endophytic fungi and in planta suppressiveness to plant parasitic nematodes. Biological Control 46: 15-23.

Silvestro D, Michalak I. 2012. raxmlGUI: A graphical front-end for RAxML. Organisms Diversity and Evolution 12: 335-337.

Simmons MP, Ochoterena H, Carr TG. 2001. Incorporation, relative homoplasy, and effect of gap characters in sequence-based phylogenetic analysis. Systematic Biology 50: 454-462.

Spatafora JW, Sung GH, Sung HM, Hywel-Jones L, White JF. 2007. Phylogenetic evidence for an animal pathogen origin of ergot and the grass endophytes. Molecular Ecology 16: 1701-1711.

Staden R, Beal KF, Bonfield JK. 2000. The Staden package, 1998. Methods in Molecular Biology 132: $115-130$.

Stamatakis A. 2014. RAxML version 8: a tool for phylogenetic analysis and post-analysis of large phylogenies. Bioinformatics 30: 1312-3. 
Tamura K, Stecher G, Peterson D, Filipski A, Kumar S. 2013. MEGA6: Molecular Evolutionary Genetics Analysis version 6.0. Molecular Biology and Evolution 30: 2725-2729.

Vega, F. E. 2008. Insect pathology and fungal endophytes. Journal of Invertebrate Pathology 98: 277279.

Vilgalys R, Hester M. 1990. Rapid genetic identification and mapping of enzymatically amplified ribosomal DNA from several Cryptococcus species. Journal of Bacteriology 172: 4238-4246.

Walsh E, Luo J, Naik A, Preteroti T, Zhang N. 2015. Barrenia, a new genus associated with roots of switchgrass and pine in the oligotrophic pine barrens. Fungal Biology 119: 1216-1225.

Walsh E, Luo J, Zhang N. 2014. Acidomelania panicicola gen. et. sp. nov. from switchgrass roots in acidic New Jersey Pine Barrens. Mycologia 106: 856-864.

Wang Z, Binder M, Schoch CL, Johnston PR, Spatafora JW, Hibbett DS. 2006. Evolution of helotialean fungi (Leotiomycetes, Pezizomycotina): a nuclear rDNA phylogeny. Molecular Phylogenetics and Evolution 41: 295-312.

White TJ, Bruns T, Lee S, Taylor JW. 1990. Amplification and direct sequencing of fungal ribosomal RNA genes for phylogenetics. In: Innis MA, Gelfand DH, Sninsky JJ, White TJ, eds. PCR Protocols: A guide to methods and applications, New York: Academic Press Inc.p. 315-322.

Young ND, Healy J. 2003. GapCoder automates the use of indel characters in phylogenetic analysis. BMC Bioinformatics 4: 6.

Yuan Z, Verkley GJM. 2015. Pezicula neosporulosa sp. nov. (Helotiales, Ascomycota), an endophytic fungus associated with Abies spp. in China and Europe. Mycoscience 56: 205-213.

\section{FIGURE LEGENDS}

Figure 1. Colonies of Polyphilus species on MMN (above), CMA (middle) and PDA (below) media. A-C: P. sieberi (REF052); D-F. P. frankenii (REF050).

Figure 2. Maximum Likelihood (RAXML) tree of concatenated ITS, LSU, SSU and RPB2 sequences of representative isolates of Polyphilus species and related fungi (best blast matches, and representative taxa of related lineages) from Hyaloscyphaceae s. 1. (Helotiales). Bayesian posterior probabilities $(\geq 0.90)$ are shown above branches and before slashes; RAXML bootstrap support values $(\geq 70)$ are shown below branches and after slashes. Type strains are shown in bold. Phialocephala fortinii (CBS 443.86) served as an outgroup. The scale bar indicates expected changes per site per branch.

Figure 3. (Fig S1?) Maximum Likelihood (RAXML) tree of Polyphilus species built using concatenated ITS, LSU, SSU and RPB2 sequences with coded indels for the ITS region. Bayesian posterior probabilities $(\geq 0.90)$ are shown above branches and before slashes; RAXML bootstrap support values $(\geq 70)$ are shown below branches and after slashes. Type strains are shown in bold. Roseodiscus subcarneus (voucher 314a) served as an outgroup. The scale bar indicates expected changes per site per branch. 
Figure 4. Maximum likelihood (RAXML) tree of ITS sequences of representatives of Polyphilus species and similar sequences from GenBank. Sequences obtained in this study are shown in bold. After the accession number and sequence name, the host, isolation source and geographic origin of each sequence is shown in brackets. Bayesian posterior probabilities $(\geq 0.90)$ are shown above branches and RAXML bootstrap support values $(\geq 70)$ are shown below branches. Roseodiscus subcarneus (voucher D. Haelew 314a, KT92714) was used as an outgroup. Abbreviations: uncultured (u.), clone (c.), isolate (is.), strain (st.), voucher (v.), surface sterilized (s. s.) ectomycorrhizal (EcM.). Sequences of uncultured fungi are marked by diamonds $(\bullet)$. The scale bar indicates expected changes per site per branch.

Figure 5. Pathogenicity of Polyphilus sieberi sp. nov. towards Heterodera filipjevi. A-C) Fungusinfected eggs originally isolated from field-collected symptomatic cysts, detailing hyphal cells. D) Symptomatic cyst obtained from in vitro tests, containing blackish eggs infected with the fungus. E) Runner hyphae of $P$. sieberi growing in cyst mucilage. $\mathrm{F}-\mathrm{H})$ In vitro infection process of $P$. sieberi in nematode eggs: hyphae forming enlarged, thick-walled and lobate cells containing oil-like bodies. Note the pigmentation process during the early (F, G) and late $(\mathrm{H})$ stages of colonization. I, J) Fungal colonization observed in slide cultures: (I) runner hyphae that penetrated the nematode egg enlarged and became filled with distinct oil-like bodies; (J) penetration of hyphae through the body cuticle and the mouth opening of a nematode juvenile, detailing the formation of enlarged hyphal cells inside the body cavity (J). (arrowed: nematode stylet). Scale bars: A, C, F-J $=30 \mu \mathrm{m} ; \mathrm{B}, \mathrm{E}=10 \mu \mathrm{m}$; D = 0.6 $\mathrm{mm}$. 